ARTICULO

Revista Derecho - Año 2 edición 3: 81 - 105

Web: http://www.revistaderecho.pe E-mail: editorial@revistaderecho.pe

ISSN 2313-6944

\title{
EL TERRITORIO COMUNAL COMO EXTERNALIDAD ECONÓMICA Y LA SEGURIDAD JURÍDICA EN LOS ACTOS DE DISPOSICIÓN DE LA PROPIEDAD EN LAS COMUNIDADES CAMPESINAS DE PUNO
}

Waldyr Wilfredo Alarcón Portugal ${ }^{*}$

INFORMACIÓN DEL ARTICULO

Art. Recibido: 25/01/16

Art. Aceptado: 03/06/16

Art. Publicado: 18/12/18

PALABRAS CLAVE:

Comunidad campesina

Desarrollo

Eficiencia normativa Elección pública

Función económica

Propiedad individual Seguridad jurídica Territorio comuna

\section{RESUMEN}

El presente trabajo de investigación intitulado EL TERRITORIO COMUNAL COMO EXTERNALIDAD ECONÓMICA Y LA SEGURIDAD JURÍDICA EN LOS ACTOS DE DISPOSICIÓN DE LA PROPIEDAD EN LAS COMUNIDADES CAMPESINAS DEL DEPARTAMENTO DE PUNO, fue realizado para identificar al territorio comunal como externalidad y surge como consecuencia de que algunas comunidades se encuentran parceladas de hecho, avalados por actos jurídicos nulos generalmente escriturados y sobre posiciones entre el plano individual y comunal en los Registros Públicos, consecuentemente ello afecta a las pretensiones económicas y limita los derechos del adquiriente, al no poder acceder a la inscripción registral. $\mathrm{Al}$ apreciar tal fenómeno jurídico social, utilizamos al análisis económico del derecho como herramienta o metodología que es aplicada, a estos problemas de carácter jurídico, mediante principios y conceptos de orden económico. Esta metodología es aplicada junto con la Teoría de la Elección Pública materializada en una política pública como ciencia y arte de gobernar. Con la finalidad de conseguir seguridad Jurídica y predictibilidad, ya que la informalidad impide a los países tercermundistas como el nuestro beneficiarse del capitalismo cayendo en la incapacidad de producir capital. El objetivo fundamental de ésta investigación es formular las bases argumentativas para una reforma del marco normativo del territorio comunal y reforzar la seguridad jurídica como valor económico de la propiedad inscrita. A la luz de los principios del Análisis de Económico del Derecho, que es en buena cuenta, el análisis económico de

Abogado, Licenciado en Educación, Profesor de la Escuela profesional de Derecho de la Universidad Nacional del Altiplano. 
las Instituciones legales se ha determinado que el Territorio Comunal se constituye en una externalidad económica que afecta directamente al comunero y que esta situación amerita reformas normativas inmediatas, que como políticas públicas el gobierno debe implementar.

\section{THE COMMUNAL TERRITORY AS ECONOMIC EXTERNALITY AND LEGAL SECURITY IN THE ACTS OF DISPOSITION OF PROPERTY IN THE PEASANT COMMUNITIES OF PUNO}

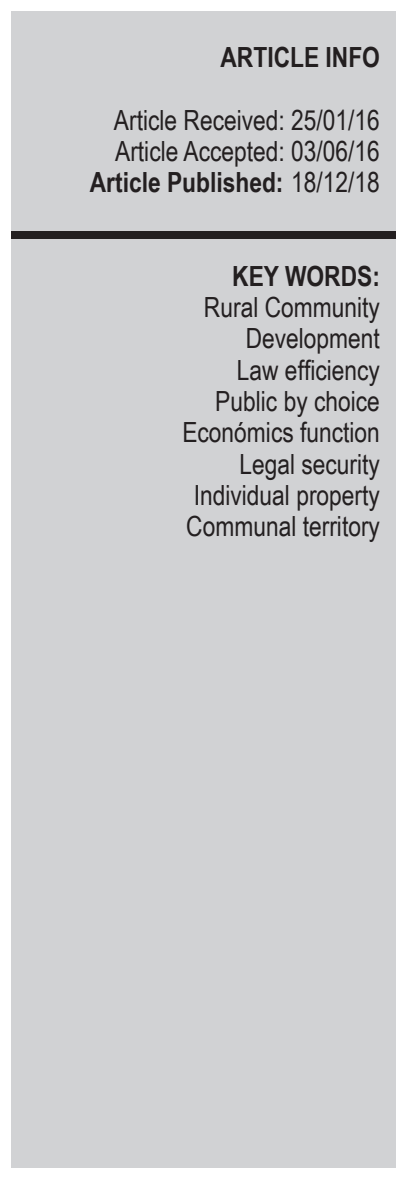

\section{ABSTRACT}

The present investigation work entitled THE COMMUNAL TERRITORY AS ECONOMIC EXTERNALITY AND THE LEGAL SECURITY IN THE ACTS OF DISPOSITION OF THE PROPERTY IN THE PEASANT COMMUNITIES OF THE DEPARTMENT OF PUNO, was made to identify the communal territory as an externality and arises as a result of which some communities they are parceled in fact, endorsed by null legal acts generally notarized and on positions between the individual and communal plans in the Public Registries, consequently this affects the economic claims and limits the rights of the acquirer, by not being able to access the registration. In assessing such social legal phenomenon, we use the economic analysis of law as a tool or methodology that is applied to these problems of a legal nature, through economic principles and concepts. This methodology is applied together with the Theory of Public Choice materialized in a public policy as science and art of governing. In order to achieve legal security and predictability, since informality prevents Third World countries like ours from benefiting from capitalism falling into the inability to produce capital. The fundamental objective of this investigation is to formulate the argumentative bases for a reform of the normative frame of the communal territory and to reinforce the legal security like economic value of the inscribed property. In light of the principles of Economic Analysis of Law, which is in good account, the economic analysis of legal institutions has determined that the Communal Territory is an economic externality that directly affects the community and that this situation merits reforms immediate regulations, that as government policies must be implemented by the government. 


\section{INTRODUCCIÓN}

Promulgada la Ley 24657 Ley de Deslinde y Titulación, se dio inicio al proceso por el cual las Comunidades Campesinas de Perú establecen sus linderos, áreas y colindancias con sus similares o no, procedimiento que conduce a la Titulación y luego goza de seguridad jurídica en el Registro de Predios con la correspondiente inscripción.

Ello no ocurrió estrictamente hablando. La mayoría de las Comunidades Campesinas hasta antes del Proceso de Reforma Agraria, únicamente contaban con tierras originarias o adquiridas por derecho propio, luego de ello fueron añadidas las adjudicadas en el proceso de Reforma Agraria, sin embargo los habitantes de una Comunidad Campesina eran propietarios que podían y pueden aún acreditar su derecho de propiedad contenidos en instrumentos públicos o privados sobre pequeñas parcelas conducidas desde ancestro por ellos, sus padres y los padres de sus padres. Fueron ellos y sin saberlo - que es lo peor- quienes a falta de territorio comunal tuvieron que desprenderse de sus pequeñas parcelas para formar uno, borrar los linderos que por décadas y hasta siglos supieron organizar y respetar hasta que una tarde cualquiera de aquellos años en los que si el poblador del campo no tenía el estatus de "comunero" no recibía las dádivas con afán político muy bien disfrazada de asistencia social de las cuales a la larga sus otorgantes obtuvieron réditos políticos hábilmente aprovechados, heredándoles para el futuro a los "comuneros" la gran desigualdad frente a otros que no lo son, excluidos de toda posibilidad de usar sus parcelas de la mejor manera y obtener de ellas el mejor provecho para sí y para los suyos.

Sabido es, que uno de los agentes económicos fundamentales del país son las economías familiares, y dentro de éstas y aunque algunos no quieran admitirlo, se encuentran las economías familiares del medio rural dedicadas fundamentalmente a las actividades económicas vinculadas a labores agrícolas como la agricultura y ganadería, los comuneros hoy en tiempos en los que se habla de inclusión, se ven privados de ejercicio de los derechos inherentes a la Propiedad consagrados en el Artículo $923^{\circ}$ del Código Civil.

De esta manera y a la luz de la metodología del Análisis Económico del Derecho y los principios que los sustentan, al tratarse de una materia interdisciplinaria, con elementos no sólo jurídicos y económicos, sino también estadísticos, antropológicos, sociológicos, filosóficos e históricos, tiene un carácter mucho más integral que otras materias que tienen por objeto una sola disciplina, seguro estoy que permitirá que lo que como hipótesis planteamos llegará a buen término: Determinar que el Territorio Comunal, así descrito, desde su peculiar manera de constituirse hasta la actualidad se ha devenido en una Externalidad Económica que directamente afecta a individuos de un segmento poblacional por siglos olvidado, el Comunero. 
Así las cosas y del análisis de los partes notariales que en oficios Notariales de las Provincias de El Collao y Chucuito, se realizan actos traslaticios de dominio sin posibilidad de acogida registral, como tercer nivel de Seguridad Jurídica, debido a incongruencias fácticas y legales, como es la Titulación a favor de persona jurídica llamada Comunidad Campesina.

En este escenario, el comunero se encuentra en evidente desventaja frente al poblador rural que no lo es, y cuya organización a la que pertenece no es precisamente una Comunidad Campesina sino más bien una Parcialidad y que sin mayor dificultad que la planteada por el Reglamento de Inscripciones del Registro de Predios obtiene acogida Registral, que finalmente coadyuva con los intereses económicos del poblador.

Identificado el territorio comunal como una externalidad económica negativa o lo que en economía se conoce como deseconomía externa, es tiempo de pensar en una reforma del marco normativo del territorio comunal y reforzar la seguridad jurídica con la intervención necesaria del Estado a fin de implementar una política pública conducente a reconocer en el comunero y su familia como un agente económico importante con posibilidad de inserción en el mercado, teniendo como sustento la propiedad del suelo y el valor económico de la propiedad inscrita en un registro jurídico.

Consideramos que con esta breve introducción, queda acreditada la relevancia y actualidad del problema que da origen a la presenta investigación y queda plenamente justificada la necesidad de aportar iniciativas que permitan lograr mayor eficiencia del sistema de transferencia de propiedad peruano.

\section{MATERIALES Y MÉTODOS}

Atendiendo al tipo de Investigación, es posible definirla como una investigación científico social, para el logro de cada uno de los tres objetivos específicos, se ha empleado los siguientes métodos:

a) Descriptivo-Explicativo. Ésta investigación puede considerarse como Descriptiva de Documentos, por cuanto gran parte de la información que analizaremos se encuentran en documentos impresos o digitalizados, bibliográficos, hemerográficos, jurisprudenciales, entre otros, y es que hablamos de una técnica de investigación para la descripción objetiva, sistemática y cuantitativa del contenido manifiesto de las comunicaciones con el fin de interpretarlos. Al buscar ésta investigación, determinar o precisar los defectos o consecuencias que se derivan de la situación actual, el presente trabajo puede ser considerado como Explicativo.

b) Analítico. Partiendo de la consideración que el Derecho puede ser estudiado como "una ciencia social reguladora de conductas que se establece para conducir a los hombres hacia determinados 
fines de progreso, paz y armonía individual y colectiva", entonces la posibilidad de buscar analizar y evaluar la finalidad y funcionamiento del Derecho.

c) Interpretación sistemática. De las normas concurrentes, involucradas en el tema de regulación normativa del Territorio Comunal vinculada a diversas ramas del Derecho que son considerados como los Materiales. Mediante el método sistemático el sentido de la ley es deducido de la posición en la que se sitúa la norma a interpretar en relación con el conjunto del sistema. Aquí, resulta indispensable la interpretación de la Constitución Política del Perú, el Código Civil (Dec, leg. 295), la ley General de Comunidades Campesinas (Ley 24656), la Ley de Deslinde y Titulación de Comunidades Campesinas (Ley 24657), la Ley de Tierras (Ley 26505).

d) Adoptar la metodología del Análisis Económico del Derecho, para reformar el marco normativo del territorio comunal y reforzar la seguridad jurídica como valor económico de la propiedad inscrita, en las Comunidades Campesinas del Departamento de Puno.

\section{DISCUSIÓN Y RESULTADOS}

\subsection{Antecedentes}

Según la información proporcionada por Francisco Tipula Mamani,
Director de la Dirección de Titulación y Catastro Rural de Puno el año 2012 en el Departamento de Puno, existen reconocidas un total de 1,256 Comunidades Campesinas, personas jurídicas creadas por Ley - por Ley 24656; Ley General de Comunidades Campesinas, éste mismo funcionario nos indica que existe un total de 1,050 Títulos de Propiedad otorgados a las Comunidades por el Estado al amparo de la Ley 24657 Ley de Deslinde y Titulación, e inscritos en el Registro de Predios de la Oficina de los Registros Públicos de Puno (Entrevista Personal con Tipula 2012).

Sin embargo el modo de tenencia de la Tierra es colectivo, común a todos, la tierra pertenece a la persona Jurídica llamada Comunidad Campesina y no al comunero, no obstante la existencia de documentación probatoria que acredita el derecho de propiedad del comunero y de manera natural lo hace valer individualmente.

En este escenario, con certeza podemos afirmar que la presente investigación, no tiene antecedentes a nivel nacional e internacional, estrictamente hablando, sin embargo y dado el uso metodológico del Análisis Económico del Derecho en la identificación del Territorio Comunal como la Externalidad económica, encontramos el importante trabajo de investigación realizado por el Instituto Libertad y Democracia (ILD) a nivel nacional, para conocer la situación Legal de las Comunidades Campesinas y Nativas del Perú, así, el Dr. Luis 
Aliaga, Senior Consultant, miembro del Instituto Libertad y Democracia de Hernando de Soto, de las Oficinas de los Registros Públicos de Puno y las propias Comunidades Campesinas del Departamento de Puno, ha recogido valiosa información, que luego se traduciría en un Documento para alcanzar al Gobierno en procura de gestar una política pública. (Entrevista Personal con Aliaga 2012).

Es necesario, enfatizar que la propuesta investigativa nuestra, pone en vitrina un tema capital en el desarrollo económico e integral de nuestra región, problema no desarrollado, ni planificado por autoridades, nacionales, regionales y locales, digo esto porque, para el inicio del cambio, es necesaria la voluntad política, encaminada mediante una política pública, que sirva de base a políticas de estado como, la demarcación territorial, ordenamiento territorial, regionalización y la muy mentada descentralización.

\subsection{Marco referencial}

\subsubsection{De orden Constitucional}

\subsubsection{Principio de Supremacía Cons- titucional}

Es la garantía de relación de supra y de subordinación de todo el ordenamiento jurídico determinado a la constitución positiva. Dividiéndose en los siguientes principios (GUASTINI, 2008):
a) Principio de Unidad.
b) Principio de Razonabilidad.
c) Principio de Control.

\subsubsection{Principio de Corrección Fun- cional}

Tal y conforme lo ha sostenido el Tribunal Constitucional, en virtud al principio de corrección funcional, debe respetarse el ámbito de las competencias y atribuciones constitucionalmente asignadas a cada Poder y órgano del Estado, pues es este el que determina el margen funcional de cada uno de ellos. No debemos dejar de mencionar, sin embargo, que para interpretar los alcances de las normas de atribución contenidas en la propia Constitución es necesario tener en cuenta aquellas otras normas subconstitucionales (entiéndase leyes orgánicas) que, dentro del marco constitucional, se hayan dictado para determinar la competencia o las atribuciones de los Órganos del Estado o el ejercicio de los derechos fundamentales de la persona. Esta especie de "bloque de constitucionalidad" le da especial sustento al principio de corrección funcional que se encuentra plasmado en el artículo 79 del Código Procesal Constitucional (FARRANDO, 2000).

\subsubsection{Comunidad campesina y te- rritorio comunal}

Las comunidades campesinas y las comunidades nativas son organizaciones legales reconocidas constitucionalmente en el Perú desde 1920. De esa misma época data el tratamiento proteccionista de sus tierras, el cual se mantuvo sin mayores alteraciones por más de setenta años.

En 1987, durante el primer gobierno del Presidente Alan García, se 
aprobó la Ley General de Comunidades Campesinas, Ley Nro. 24656, y la Ley de Deslinde y Titulación del Territorio Comunal, Ley 24657, dándose así un fuerte impulso al reconocimiento de sus derechos.

En 1993, la nueva Constitución Política, manteniendo el reconocimiento de la existencia legal y de la autonomía de las comunidades, recortó el régimen de protección de sus tierras y les reconoció la facultad de disponer libremente de ellas. La modificación se orientaba a permitir a las comunidades campesinas y nativas ejercitar en forma plena, al igual que cualquier propietario de tierras, las facultades del derecho de propiedad, asumiendo que el mantenimiento de la propiedad en forma colectiva era una de las causas de su pobreza.

Dos años después, la Ley $\mathrm{N}^{\circ}$ 26505, mejor conocida como Ley de Tierras, desarrolló la norma constitucional, señalando los requisitos para que las comunidades pudieran disponer de sus tierras como mejor creyeran conveniente. Aunque la Ley menciona diversas posibilidades como la venta de tierras a terceros, arrendamiento o hipoteca, la principal forma de disposición que aparece para los integrantes de las comunidades es la adjudicación en propiedad de las parcelas que poseen. La complejidad del tema y la falta de una mayor reglamentación han llevado, sin embargo, a que en la sierra del Perú (lugar donde se concentra la mayor cantidad de comunidades campesinas) sean más las expectativas de los comuneros por obtener su título individual que los pasos concretos tomados en esa línea.

Este importante cambio operado respecto de las tierras comunales guarda relación con las modificaciones operadas en el tratamiento de las tierras de los ejidos en México, en el año de 1992, para permitirles también disponer de sus tierras. En años recientes se ha producido en el Perú una serie de cambios menores en la legislación sobre comunidades. Pero la más importante fue la contenida en el Decreto Legislativo No 1015 (modificado por el Decreto Legislativo No 1073), derogado en setiembre de 2008 por la Ley No 29261.

En lo que a las comunidades campesinas se refiere el tema dista mucho de estar zanjado. En efecto, mientras no se culmine con la formalización de las tierras comunales y que, de forma complementaria, se adopten políticas que permitan a estas organizaciones enrumbar firmemente hacia su desarrollo, poco será lo que resulte de leyes como la mencionada Ley de Tierras.

\subsubsection{Territorio Comunal}

El territorio comunal está integrado por las tierras originales de la comunidad, las tierras adquiridas de acuerdo al derecho común y agrario, y las adjudicadas con fines de reforma Agraria. Las tierras originarias comprende: las que la Comunidad viene poseyendo, incluyendo las eriazas, y las que indican sus títulos. En caso de controversia sobre esos títulos, el Juez competente calificará dichos 
instrumentos. Así lo señala la Ley № 24656.

No se consideran tierras de la Comunidad;

a) Los predios de propiedad de terceros amparados en títulos otorgados anterioridad al 18 de Enero de 1920 y que se encuentran conducidos directamente por sus titulares;

b) Las tierras que al 6 de Marzo de 1987 se encuentren ocupadas por centros poblados o asentamientos humanos; salvo aquellas sobre las que se hayan planteado acciones de reivindicación por parte de las comunidades Campesinas; Se exceptúan las tierras de los centros poblados que estén formados, dirigidos y gobernados por la propia comunidad;

c) Las que el Estado ha utilizado para servicios públicos; salvo convenios celebrados entre el Estado y la Comunidad;

d) Las tierras adjudicadas con fines de Reforma Agraria, excepto:

1. Aquellas sobre las que se hayan planteado acciones de reivindicación por parte de las Comunidades Campesinas.

2. Aquellas que sean sometidas a procesos de reestructuración con fines de redistribución de tierras a favor de las Comunidades Campesinas; $y$,

e) Las tierras en que se encuentren restos arqueológicos.

\subsubsection{Tierras Comunales}

El tratamiento de las tierras comunales está concentrado en la Ley de Deslinde y Titulación del Territorio Comunal, Ley No 24657. Esta es una ley especial que fue dada en 1987 para solucionar uno de los mayores problemas de estas organizaciones, la falta de títulos y la falta de inscripción de los mismos en los Registros Públicos de la propiedad.

Desde 1920 hasta 1993 las tierras de las comunidades estuvieron protegidas por un tratamiento constitucional especial, por el cual se declaraba sus tierras como inalienables, inembargables e imprescriptibles. En ese marco constitucional (reiterado en la Constitución de 1979) la Ley General de Comunidades Campesinas, Ley No 24656 deriva el tratamiento de las tierras comunales a la Ley de Deslinde y Titulación.

Dicho marco constitucional y legal se vio alterado profundamente con la entrada en vigencia de la Constitución Política de 1993, la cual dejó vigente tan sólo el carácter imprescriptible de las tierras comunales, con la excepción del abandono de tierras. Al mismo tiempo, la nueva Constitución amplió la autonomía comunal a la libre disposición y uso de las tierras comunales.

En 1995, con la dación de la Ley No 26505, conocida como Ley de Tierras, se desarrolló el artículo 89 de la Constitución, facultando a las comunidades campesinas y nativas a disponer de sus tierras en la forma 
que ellas creyeran conveniente, cuidando simplemente que la decisión sea tomada en Asamblea General. Dicha Ley distinguió entre comunidades campesinas de la costa a las que dedicó el artículo 10 y las comunidades campesinas y nativas de la sierra y selva del artículo 11.

El Reglamento de la Ley de Tierras no abordó estos temas, pero en 1997, mediante la Ley de Titulación de Tierras de las Comunidades Campesinas de la Costa, Ley No 26845, se desarrolló el artículo 11 de la Ley de Tierras, modificándolo, para facilitar la adjudicación de las tierras a los comuneros.

La Ley No 26845, pendiente de reglamentación pese a los años transcurridos, se refiere sólo a las comunidades costeñas, pero en su parte final modifica el artículo 2 de la Ley de Deslinde y Titulación del Territorio Comunal, con lo cual sus efectos son generales para todas las comunidades, en este último aspecto.

Adicionalmente, algunas leyes promulgadas entre 2004 y 2006, como la Ley No 28685, permiten declarar el abandono legal de las tierras de las comunidades campesinas de la costa.

Más recientemente, en mayo de 2008, dentro del casi centenar de decretos legislativos, el gobierno de García promulgó el Decreto Legislativo 1015 , por el que se igualaba los requisitos para que las comunidades campesinas de la sierra y las comunidades nativas pudieran disponer más fácilmente de sus tierras. Las críticas llevaron a que mediante el Decreto Legislativo No 1073 se hiciera un pequeño cambio, pero las protestas de las organizaciones indígenas llevaron a que en setiembre del mismo año se derogara esos decretos, mediante la Ley No 29261.

En materia de tierras comunales debe mencionarse el Decreto Legislativo No 838, por el cual se permitió la adjudicación en forma gratuita de tierras del Estado a comunidades e individuos, en zonas afectadas por la violencia política y de economía deprimida. Lo excepcional de la norma era que se exoneraba a los beneficiarios de pagar por la tierra adjudicada, pero su vigencia fue bastante breve.

De esta manera, se encuentran plenamente vigentes algunas normas legales que fueron promulgadas antes de la actual Constitución, junto con otras aprobadas después. En ciertos aspectos esa coexistencia plantea problemas de interpretación y de aplicación.

\subsubsection{Actos de Disposición de la Pro- piedad dentro del territorio co- munal}

La existencia de comunidades campesinas en el departamento de Puno, que se encuentran parceladas de hecho, es una realidad innegable, la cual trae como consecuencia, la disposición de la propiedad del territorio comunal amparada en la informalidad.

Sin embargo hechos jurídicos son avaladas por actos jurídicos nulos 
y sobre posiciones entre el plano individual y comunal en Registros Públicos, consecuentemente afectando sus pretensiones económicas y limitando sus derechos, al no poder acceder a la inscripción registral (AROCA, 2008).

Estos actos de disposición, que se encuentran en la jurisdicción de la informalidad y afectados por una nulidad insubsanable, por falta de manifestación, ausencia de agente capaz, finalidad ilícita y objeto física y jurídicamente imposible, son los, los recogidos también por nuestro ordenamiento jurídico, pero con la diferencia que son inválidos e ineficaces, son los siguientes:

- Compra venta

- Permuta

- Donación

- Mutuo

- Arrendamiento y demás actos jurídicos que están amparados en el Código Civil

- Anticipo de Legítima

Dichos actos de disposición, se reflejan en la realidad social y algunos de los contratos de compraventa, son adjuntados en los anexos (DE SOTO, 2004).

\subsubsection{Análisis económico del dere- cho}

\subsubsection{Antecedentes históricos}

Los orígenes de la economía moderna se remontan a 1776 , año en que Adam Smith publicó "Investigación sobre la naturaleza y causa de la riqueza de las naciones". En este libro,
Smith describió los principios básicos de una economía de mercado. Smith puede considerarse el fundador de la disciplina de la microeconomía, rama de la economía que se ocupa de la conducta de las entidades económicas individuales: mercados, empresas y economías domésticas. En "La riqueza de las naciones", Smith consideró cómo se fijan los precios de los bienes y servicios, cómo se fijan los precios de tierra, trabajo y capital (recursos de producción) e investigó las virtudes y los defectos del mecanismo del mercado, identificó notables propiedades eficientes de los mercados. La "mano invisible" que extrae un bien común de los actos interesados de cada individuo que conforma una economía.

Las dos corrientes - la microeconomía y la macroeconomía - convergen y forman la economía moderna. Antes la frontera entre ambas era muy nítida, actualmente, las dos vertientes se han fusionado al aplicarse herramientas microeconómicas al análisis de problemas macroeconómicos como inflación y desempleo. Sin embargo, para comprender la teoría económica, es necesario estudiar ambas ramas por separado.

POSNER, (1998) ha apuntado que muchas áreas del Derecho tienen el sello del razonamiento económico, así la teoría de la eficiencia del Derecho se explica mejor como un sistema para maximizar la riqueza de la sociedad y proclama a la teoría económica del Derecho como la teoría positiva del Derecho más prometedora que existe en la actualidad. 
El Análisis Económico del Derecho tiene sus raíces en los años sesenta en los trabajos de sus fundadores Coase y Calabresi (otros también consideran a Posner como fundador) en forma paralela en dos Universidades: Chicago y Yale respectivamente.

Coase en su clásica obra siempre citada "The Problem Social Cost", plantea el conocido teorema de Coase, descubriendo y clarificando el significado de los costes de transacción y los derechos de propiedad para la estructura institucional y el funcionamiento de la economía. También analizó la eficacia de la norma jurídica en términos de costo-beneficio. Además su obra constituye una crítica a la tesis de Pigou en cuanto a la intervención del Estado en la economía.

Por su parte CALABRESI (1996) emplea la teoría económica como criterio de imputación del Derecho de los Daños. Así: “....En el articulo de Calabresi resalta la aplicación de la teoría económica en la tarea de definir los fines que ha de perseguir el derecho de la responsabilidad así como para evaluar cuales son las normas o reglas mas eficaces para conseguir el objetivo fijado". Sin embargo el antecedente inmediato del Análisis Económico del Derecho, antes que Calabresi y Coase, se encuentra en la aplicación de la teoría económica en leyes Antimonopolios, impuestos y daños monetarios, en todo caso en las aulas de la universidad de Chicago y Yale se sistematizaron y germinaron el pensamiento jurídico anglosajón del Análisis Económico del Derecho, gracias a los ensayos del economista Premio Nobel de Economía 1991 Ronald Coase y Calabresi.

Otro hito importante en el desarrollo del Análisis Económico del Derecho, esta en los trabajos de Posner en los años setenta, por la cual sistematiza el análisis de la teoría microeconómica a todas las ramas del sistema jurídico, nunca antes ensayadas, aplicando el análisis económico al derecho de familia, la discriminación racial, la jurisprudencia y la privacidad y de esta manera con su trabajo titulado "Economic análysis of Law", contribuye en el desarrollo autónomo del Análisis Económico del Derecho. Propuso y defendió la idea de que la ley puede ser explicada mejor bajo el supuesto de que los jueces tratan de promover la eficiencia económica y la maximización de la riqueza como objetivo de la política legal y social.

En los años ochenta el Análisis Económico del Derecho, deja de ser un fenómeno intelectual accidental para convertirse en una institución autónoma del pensamiento jurídico que traspasa las fronteras del mundo anglosajón, sin embargo en el Perú en los años noventa recién se considera al Análisis Económico del Derecho como una tendencia importante en el ambiente jurídico, y a decir de $\mathrm{Bu}$ llard con los aportes del Instituto Libertad y Democracia encabezado por De Soto, el pensamiento de Coase se aplica en la realidad peruana con una serie de medidas políticas para eliminar en lo posible los costos de transacción de la economía informal como 
realidad peruana, un ejemplo de ello es la constitución del Instituto Nacional de Defensa de la Competencia y Protección de la Propiedad Intelectual INDECOPI en 1992.

\subsubsection{Concepto de Análisis Económi- co del Derecho}

En el libro "Introducción al Análisis Económico del Derecho" (ROEMER, 1994) menciona que el derecho y la economía se definen como la aplicación de la teoría económica y de los métodos econométricos para examinar la formación, estructura, procesos e influencia de la ley y de las instituciones jurídicas. Como tal, uno de los principales portavoces de la perspectiva tradicional del movimiento del derecho y la economía, ha observado que la disciplina se ha dividido en dos ramas (ROEMER, 1994)

El desarrollo de la primera rama ha corrido a la par de la maduración de la economía como ciencia y de la expansión de la regulación gubernamental de la economía. Adam Smith, al observar las conspiraciones que se unían para restringir el comercio, dio pie a la creación de una legislación antimonopólica que proporción un cuerpo muy sofisticado de economía del derecho. Un desarrollo histórico similar puede rastrearse en campos tales como la regulación de los servicios públicos, patentes, derechos de autor y tributaciones, así como la regulación de las finanzas corporativas y del comercio internacional (ROEMER, 1994)

La otra rama del análisis económico de la ley ha tenido una historia más variada. Comenzó en un plano muy alto con el trabajo de Bentham. Este autor fue uno de los pioneros y hasta recientemente, uno de los pensadores que indicaron que los individuos actuaban como maximizadores racionales de sus propios intereses en todos los aspectos de la vida. El creyó, que el modelo económico, percibido como la simple elaboración de las implicaciones que resultan de suponer que las personas son maximizadoras racionales de sus satisfacciones, podrirán aplicarse a todos los campos de la actividad humana, en vez de quedar confinado a los mercados explícitos de la economía.

Es así como estos dos grandes pensadores de las teorías económicas clásicas dan las bases para que se dé el concepto y nacimiento de lo que hoy conocemos como Análisis Económico del Derecho.

\subsubsection{Precisiones Conceptuales}

El Análisis Económico del Derecho es una relativamente nueva escuela del pensamiento jurídico, que ha aparecido en los países anglosajones con base en la evolución del pensamiento económico, en especial entre 1930 y 1970.

Según COOTERy ULEN (1998) "El análisis económico del derecho es un instrumento interdisciplinario que ofrece dos grandes campos de estudio y facilita una mayor comprensión de ambos. La economía puede considerar el derecho de manera extremadamente útil, tanto para los abogados como para cualquier persona interesada en 
asuntos de política pública. Predomina la costumbre de pensar que las normas jurídicas se limitan a ser instrumentos de justicia. Análogamente, el punto de vista común es que la economía no necesita más reglas que las propias." Se trata de una metodología que aplica, a problemas de carácter jurídico, principios y conceptos de orden económico, la relevancia de los derechos de propiedad en la eficiencia de la asignación de los recursos, la función de eficiencia de las normas y la aplicabilidad del análisis económico a toda clase de transacciones, incluso las que no se realicen en un contexto de mercado. Otro concepto es el intercambio voluntario como forma eficiente de transacción, según distintos criterios, tanto en su versión real como en su versión presunta o ficticia, habiendo varios puntos de vista respecto a esta controversia.

Según (CACHANOSKY, 1991) "El análisis económico del derecho, tal como fue desarrollado por la Escuela de Chicago parece ser más útil para determinar el monto de las penalidades que para determinar cuál de las partes tiene la razón en el conflicto. Pero aún en este caso los costos son subjetivos, de forma que la utilidad para determinar los montos de las penas también se puede ver distorsionada por este problema. Salvo que la pena esté establecida en el contrato, su determinación es siempre subjetiva. El análisis económico del derecho tal vez pueda en este caso ser una convención para determinar los montos de las penas sin caer en la subjetividad de los jueces." Dándole a la definición del análisis económico del derecho, un tono oscuro, afirmando la inexactitud de los costos y precios comparados con la subjetividad en las sentencias, suponiendo el resultado y el criterio del juez, proponiendo la determinación de los costos para así dejar a un lado esta subjetividad de la que habla el autor. Predecir los efectos económicos de las normas legales, es decir, las consecuencias de las mismas en el ámbito de las relaciones económicas. En otros términos, trata de explicar el comportamiento de las personas que participan en actividades relacionadas con las leyes y las instituciones. Esto se estudia, de forma general, a partir del modelo de elección racional, y, de modo más específico, a partir de la teoría de los precios que se sustenta en dicho modelo de comportamiento, en la medida en que los precios se constituyen en el principal sistema de incentivos que condiciona las decisiones de los agentes económicos.

\subsubsection{Entendiendo el Análisis Econó- mico del Derecho}

En primer lugar corresponde señalar que el "Análisis Económico del Derecho" no surgió como una dogmática, sino como una perspectiva analítica. Para cumplir con esa tarea, se partió de la ciencia económica, porque es la que más rigurosamente había estudiado la conducta humana y extraída reglas que la hacían predecible, otorgándole un estatus científico nada despreciable.

El estatus científico del análisis económico parte del individualismo metodológico, es decir, de las elecciones que haría el individuo a fin de 
maximizar su utilidad; se vale de las reglas de la economía para predecir esa conducta; construye un modelo sobre esas premisas y a partir de ello obtiene un poderoso instrumento de análisis modélico para el estudio de situaciones empíricas (COASE, 1994).

Esta metodología ha sido tan exitosa que ha sido utilizada en numerosos campos: contratos, responsabilidad civil, derecho de familia, derecho constitucional, filosofía política, derecho penal.

La primera cuestión que nos interesa examinar, se relaciona con las distorsiones hermenéuticas con que ha sido presentada esta escuela. La segunda hipótesis de trabajo, es señalar que hay muchos abordajes similares sobre la conducta humana que han permitido comprenderla mejor, de un modo más complejo, dejando atrás ciertas simplificaciones a las que llevó el análisis económico del derecho.

\subsubsection{Concepto de Externalidad}

Siguiendo a MISHAN, (1971) el concepto de externalidades se define en términos de la respuesta de la producción de una empresa, el beneficio (pérdida), o la utilidad (desutilidad) de una persona frente a la actividad de las otras. En otras palabras, el hecho de que exista un efecto externo quiere decir simplemente que la actividad de una unidad económica repercute sobre la actividad de otras, modificando consecuentemente la actitud que estas últimas adoptan. Esta interacción no se produce necesariamente a través del mercado, sino que reconoce un fenómeno de interdependencia directa.
El carácter fundamental de esta «interdependencia» directa es su "no intencionalidad»: el efecto no se produce en forma deliberada, sino que «resulta» como consecuencia de acciones orientadas a otros objetivos. Esta supuesta "no intencionalidad» se traduce en la forma de enfrentar el problema y, en último término, en las medidas de política económica.

\subsubsection{Movimiento}

Como movimiento, el análisis económico del derecho se desarrolló a partir de la agenda del realismo jurídico. Éste señalaba que los estudiosos del derecho deberían ocuparse de la ley tal como funciona en la práctica haciendo uso de las ciencias sociales, y que la economía era una de las ciencias sociales a la que podían recurrir los abogados académicos.

El análisis económico del derecho, una vez que ha ganado un lugar en las instituciones europeas y estadounidenses de educación jurídica, es influyente pero controvertido. "La aceptación de la teoría del análisis económico del derecho de ha facilitado mediante las similitudes estructurales entre la ciencia económica y la jurídica". El "hombre razonable" del derecho no es muy diferente del "hombre racional" de la economía. La búsqueda que hace la ley para una división justa en los costos de los accidentes no es diferente de la preocupación del economista por la asignación eficiente del riesgo (COOTER, 1998).

El Análisis Económico del Derecho, de creación anglosajona, es en 
principio una nueva visión jurídica que se da, valorando en aspecto cuantitativo los fenómenos económicos que afectan al campo del derecho, definiendo costos y demás, llegando con veinte años de retraso a Hispanoamérica y siendo discriminada en su estudio y demás.

Para el desarrollo del marco teórico las ideas principales en las obras de los expositores primarios en esta rama, destacados mundialmente, así como doctrinarios peruanos, que si bien en un principio no se le dio la importancia debida, hoy es un punto de estudio indispensable en el derecho moderno.

La concurrencia de principales exponentes de esta nueva corriente jurídica en sus varias fases, como: Coase, Calabresi, Posner, y Benson, además de desarrollar un marco teórico en el cual se tocaran los temas de interés académico e interés público respecto a esta disciplina.

\subsubsection{Presupuestos del Análisis Eco- nómico del Derecho}

Según TORRES, (2001), existen los siguientes presupuestos:

\section{a) Individualismo Metodológi- co.- Se basa en el análisis de la acción humana individual, ya que toma en cuenta que el in- dividuo trata racionalmente de maximizar su bienestar porque los bienes son escasos.}

b) Modelo Analítico.- Es el mercado como método de asignación de recursos, mediante la econo- mía, para su posterior aplicación al derecho.

c) Modelo Hombre Racional.- Se basa en el modelo de un hombre muy cuidadoso y previsor- ex ante, a diferencia del modelo legal- es post.

d) Nivel de Optimización.- Mejor aprovechamiento de los escasos recursos.

e) Teorema de Coase.- En resumen, reducir los costos de transacción o contratación no solo económicos.

f) Costos de Transacción.- Son los obstáculos que las partes contratantes pueden encontrar en la búsqueda de la eficiencia.

g) Costos de Oportunidad.- Son aquellos costos a los que se tiene que renunciar para conseguir algo.

\subsubsection{El Análisis Económico del De- recho y el Sistema de Valores}

Comenzando de modo jocoso, se puede dar a entender en un chiste: "Un Abogado y un Economista salen a jugar golf, al ver que los golfistas de adelante no avanzaban, le dicen al críquet que averigüe que sucede. Al rato llega y les dice: los jugadores de adelante son ciegos, el abogado responde bueno tienen derecho dejémoslo jugar a lo que el economista responde, pero mejor que jueguen en la noche" mientras el Abogado piensa bajo un Sistema de Valores del Derecho, el Economista busca la asignación eficiente de los recursos”. Expresa STIGLITZ, 
(2002) "Yo había estudiado los fallos tanto del mercado como del Estado, y no era tan ingenuo como para fantasear con que el Estado podía remediar todos los fallos del mercado, ni tan bobo como para creer que los mercados resolvían por sí mismos todos los problemas sociales." Dando una perspectiva independiente a la forma de pensar, la cual se debe adoptar para el estudio de esta nueva rama. Es necesario reinventar la Administración para hacerlo más eficiente, transparente y con rostro humano.

Según CASTILLO y VÁSQUEZ, (2006), el Análisis Económico del Derecho es criticable afirmando "Que su objetivo final no es la eficiencia, sino, la promoción y protección de los derechos y las libertades individuales", el cual está en contraposición del objetivo del derecho civil que está basado en su naturaleza de bienestar y social.

Para MALPARTIDA, (1996) "El Análisis Económico del Derecho pretende relacionar la Economía y el Derecho como un modo de abordar Interdisciplinariamente fenómenos sociales determinados". Agrega el mismo autor que "El análisis económico del derecho consiste en la aplicación del análisis económico al estudio del funcionamiento del sistema jurídico, de los problemas más importantes en el Derecho. Este análisis es un método o enfoque que se aplica a un objeto distinto de aquel para el que fue concebido el sistema económico, sustituyéndolo por el sistema jurídico. No se reemplaza el razonamiento jurídico sino se busca complementarlo. Solo busca que ampliemos nuestras perspectiva para que al decidir una controversia jurídica tomemos en cuenta no solo los costos privados que la decisión puede tener, sino al mismo tiempo los efectos económicos y sociales afirmando que es un complemento para el derecho moderno, y no una tergiversación de este mismo, que tiene que acoplarse y ser estudiado. Determinar las normas legales que son económicamente eficientes, o sea, que son más favorables a la generación o maximización de la riqueza. La Economía del Bienestar suministra el horizonte de referencias normativas en cuanto a la idoneidad económica de las normas legales.

\subsubsection{Antecedentes del Análisis Eco- nómico del Derecho en el Perú}

En toda América latina, esta nueva visión llega con 20 años de retraso, no excluyéndose al Perú, donde desde los 80 con los trabajos del Instituto de Libertad y Democracia Liderado por (DE SOTO, 2004) con su obra "El Otro Sendero" en 1986. A inicios de los 90, a treinta años de su aparición, el Análisis Económico del Derecho, comienza a ser reconocido como tendencia importante en el derecho peruano, siendo 1980 la fase inicial de esta perspectiva del derecho en su ingreso, y el comienzo del estudio y la importancia o desinterés que se le pone actualmente en nuestras aulas.

Se reafirma que en un comienzo hubo una negativa al Análisis Económico del Derecho, negando su enseñanza, así como se dio en el Perú, 
anteriormente en sus bases ocurrió similar acontecimiento, que de igual manera se terminó cediendo, de igual manera predecir cómo se forman las leyes, o sea, delimitar los factores que influyen en su proceso de su gestación. Se persigue desvelar los intercambios entre los distintos actores políticos intervinientes que tienen lugar en todo proceso de decisión pública de normas legales, lo cual nos remite a la teoría económica de la Elección Pública.

\subsubsection{Metodología del Análisis Eco- nómico del Derecho}

El análisis mostrara que algunos elementos importantes del derecho y la economía no son cualitativamente diferentes de los métodos tradicionales de las ciencias sociales, sino que amplían y mejoran esos métodos.

Los principales métodos analíticos asociados con la perspectiva, tradicional del análisis económico del derecho son:

1) Se concebirá el objeto de estudio como un sistema de restricciones y recompensas que interactúa con los individuos. Un objetivo central del cuerpo de conocimientos del derecho y la economía ha sido analizar la interacción dentro de un sistema de normas y comportamientos de los individuos, con el fin de determinar los efectos de dichas normas.

2) El propósito del análisis crítico es identificar el componente sistemático de los fenómenos y separar ese componente de los fenómenos aleatorios.
3) Los actos privados son motivados exclusivamente por el deseo de maximizar su propio interés económico. Dicha premisa se obtiene de los preceptos conductuales de la teoría de los precios, donde sus predicciones han resultado poderosas y útiles.

El énfasis en la premisa del interés propio en el análisis económico del derecho ha generado críticas sobre la base de que está inculca hábitos amorales de pensamiento.

4) La necesidad de examinar, tanto los efectos marginales como totales, con especial énfasis en los primeros, es importante para entender la respuesta huna a la ley. Dicho análisis es importante también para examinar el efecto de diversos programas de transferencia y de recursos fiscales, cuyo resultado debe calibrarse según su efecto sobre los incentivos marginales.

5) Los bienes y servicios son multidimensionales, y la regulación de una dimensión afectará las otras dimensiones del bien o servicio. Este principio es importante porque las leyes a menudo afectan únicamente un aspecto de un conjunto complejo de interacciones.

6) $\mathrm{Al}$ evaluar los efectos de la ley, es importante la respuesta transaccional privada de varios individuos. Debe observarse, más allá de las reacciones de un particular a una norma legal, las respuestas 
sistemáticas abiertas a un grupo de personas.

Aun cuando el supuesto de cero costos de las transacciones no sea realista, el teorema sugiere que no debe concluirse que las leyes tienen grandes efectos cuando las partes afectadas mantienen relaciones de regateo continuas entre ellas.

7) $\mathrm{Al}$ evaluar arreglos regulatorios del mercado, es importante compara el arreglo que se está evaluando contra otras alternativas institucionales viables. Demostrar las imperfecciones del mercado y de la administración es un simple ejercicio intelectual; pero se trata de un ejercicio de escaso interés.

8) Los informes jurídicos y los expedientes escasos contienen información útil y cuidadosamente registrada acerca de las prácticas económicas particulares.

9) El estudio dela historia jurídica y del derecho comparado es importante, ya que las indiferencias significativas en la estructura de las instituciones jurídicas solo aparecerán, probablemente, cuando existan diferencias en las condiciones de costos que la sociedad enfrenta.

\subsubsection{Seguridad Jurídica}

\subsubsection{El Registro Público de la Pro- piedad}

En el Registro Público se lleva a efecto la inscripción, con la finalidad primordial de dar al comercio jurídico la seguridad y certeza necesarias para su normal desarrollo.

Es decir, cumple la función de proporcionar publicidad a los actos jurídicos. Indica que es un "centro público donde se hace constar el estado de la propiedad inmueble por la toma de razón de todos los títulos traslativos de su dominio, precisa que "índice de los bienes situados en determinada de marcación, sus propietarios de gravámenes o derechos sobre tales bienes, mencionando titulares y cambios que en ellos realizaron. Desde muy antiguo se advirtió, que el tema era sumamente complejo, en tanto, la adquisición a titulo derivativo implica necesariamente la investigación preliminar respecto al poder de disposición invocado por el enajenante, y ante lo cual el adquiriente se halla obligado a exigir que aquel pruebe su derecho. (LACRUZ y SANCHO, 1984)

\subsubsection{Finalidad Abstracta del De- recho Registral Inmobiliario al brindar Seguridad Juridica con Justicia}

El Estado organiza un sistema que permite contar con un título formal de prueba de la propiedad, de tal manera que en un solo documento se incluya la historia jurídica del inmueble. De esta forma el comprador o acreedor hipotecario podrán gozar de certeza respecto a la adquisición que realiza $y$, en este sentido podrá asegurarse la rentabilidad de su proyecto de inversión (predictibilidad). Por lo tanto para procurar conseguir la seguridad de los adquirientes de bienes 
inmuebles, o de los que dan dinero a préstamo con garantía sobre bienes inmuebles, se ha procurado facilitar a los presuntos adquirientes y a los prestamistas con garantías de inmuebles, ciertas facilidades de investigación del estado de dichos inmuebles, tanto en lo que se refiere a su titularidad, como a su estado de cargas.

(LACRUZ y SANCHO, 1984) señalan que la finalidad primaria del Registro es la protección del tráfico, la agilización de las transacciones inmobiliarias, al suplir con una consulta las difíciles indagaciones sobre la titularidad de los derechos.

\subsubsection{Informalidad de la Propie- dad}

"Es la propiedad la que otorga un señorío pleno sobre la cosa, consistente en el poder a someterla a nuestra voluntad en todos sus aspectos y obtener de ella la utilidad que pueda prestar" (ALBALADEJO, 1994)

Con estas nociones previas del concepto de propiedad nos ayudara a profundizar el tema y descubrir su importancia, es decir que la propiedad es importante porque nos permite conocer el ámbito jurídico donde se desarrolla la persona y que posee con respecto a su patrimonio.

Enfocados específicamente a los títulos de propiedad y su inscripción en registros públicos ya que este es un problema que trae muchas consecuencias.

En muchos distritos se ve esta problemática y esto genera un atra- so en el mismo, por ser este un tema amplio nosotros nos enfocaremos en el Departamento de Puno que está en desarrollo, como tal está en proceso; ahora bien, partiendo del problema (informalidad de la propiedad inmueble).

Las consecuencias de la formalización, la primera seria que a mayor formalización de la propiedad mayores ingresos obtendríamos por ellas y; la segunda y más importante sería que habría un mayor control y optimización de la labor administrativa por parte del Registro.

\subsubsection{Antecedentes}

Durante el siglo pasado, muchos países del tercer mundo presenciaron la diversificación en las formas de tenencia de tierras que desafiaron las leyes existentes.

Esas nuevas modalidades incluían la subdivisión de parcelas en propiedades extremadamente pequeñas. Siendo instancias de propiedad informal que pueden ser descritas como formas populares de tenencia individual de tierras que el sistema formal ha excluido del comercio, $y$, por lo tanto, no pueden ser legalmente transadas en el mercado, han habido muchas transacciones, pero en muchos casos han sido realizadas fuera de la formalidad y de la legalidad, al no estar inscritas las propiedades en los registros público.

Ante esta situación, si el Estado no garantiza la revalidación de la propiedad a un titular o no reconoce la transferencia de dicha propiedad a un tercero, esa posesión se convierte en 
informal y su valor legal disminuye. No obstante, el propietario puede disfrutar del valor de uso de la propiedad, pero ésta carece de valor de cambio. Así, el ámbito donde estas propiedades pueden ser legalmente transadas es restringido, pues los propietarios tienen dificultades para defender y sacar el máximo provecho de sus predios. Comprarlos resulta complicado, pero más aún lo es registrarlos de manera sencilla y rápida, para que el tenedor de la propiedad pueda disfrutar de las ventajas de la legalidad y usarla como garantía para acceder a un préstamo, venderla sin que los compradores duden de su situación legal, alquilarla sin temor a que el inquilino pretenda quedársela o implemente usarla libremente. En otras palabras, no pueden disfrutar de los beneficios de la ley en toda su amplitud. (GONZÁLES, 2002).

\subsubsection{Clases de propiedad informal}

Existen básicamente dos tipos de propiedad informal: a) La de adquisición originaria y b) La de adquisición derivativa. El primero es aquel en el que el carácter informal proviene de la manera ilegal en que se accedió a la tierra, ya sea a través de un proceso espontáneo, de usurpación gradual o mediante una invasión planeada - a tierras que pertenecen a otros (Estado o Privados) sin que medie un acuerdo o pacto y en el que sus ocupantes lograron resistir la expulsión de manera exitosa. (GONZÁLES, 2002).

\subsubsection{Formalidad de la Propiedad}

Hay que reconocer que desde la fundación del Perú como República independiente se tiene un problema institucional que hasta hoy se mantiene porque el proceso de liberación del dominio español, en la que participaron todo los componentes socioeconómicos de la naciente república hasta el final de dicho proceso, resultó siendo hegemonizado y liderado por los sectores ligados y pertenecientes a la élite de la clase virreinal gobernante, y de algunos sectores nacionalistas, que no tenían clara la visión y misión de fundar una República con gobierno limitado y soberano.

Al final de la fundación de la República los que asumieron el poder político del Estado fueron los representantes de estos sectores quienes diseñaron un Estado y un régimen político-social, que si bien los liberaba de España, sin embargo mantuvieron intacto el sistema de exclusión y de marginación de todo de lo que podríamos llamar la sociedad indígena de las estructuras del poder del Estado. (GONZÁLES, 2002).

El proceso de institucionalización del estado, y la articulación del Perú como una República, siempre desgraciadamente ha mantenido este problema estructural y lo que es peor, se agudiza porque el estatismo actual tiene un sistema que excluye al Perú emergente, libre y emprendedor, consolidándose un sistema de poder, ilimitado, exclusivamente manejado por las élites representantes de las clases políticas tradicionales con poder económico (civiles o militares). Las fuerzas políticas que aparecieron como partidos o movimientos políti- 
cos nunca han tenido el propósito de refundar una república que incorpore una democracia limitada inspirada en derechos naturales como la vida, la libertad y la propiedad y garantizados en un régimen libre institucionalizado cuyo sustento se apoye en los individuos del Perú emergente. Este poder político que ha gobernado el Perú hasta ahora representando al poder oligárquico y estatista, siempre excluyente, ha tenido la capacidad y la astucia de, aparecer como agentes del cambio y asumir posiciones de transformación con el propósito de liderar procesos que buscaban cambiar esta realidad para truncarlos, y en realidad, para mantener su poder y con ello desviar el proceso de los cambios institucionales para limitar la acción mercantilista del Estado. Podemos señalar que el poder político virreinal evolucionó y se transformó luego en poder político oligárquico. Este poder se transformó en poder político de capitalismo de estado, burocrático, estatista y mercantilista y este, a su vez, hoy se ha transformado en un poder político exclusivamente de una economía excluyente formando un régimen mercantilista con una casta política, económica, social y militar que excluye a los sectores emergentes.

Este proceso de evolución del Perú como república mercantilista de corte oligárquico de alguna manera con Velasco en la década del 70 fue trastocada, porque es verdad que el general Velasco acabó con el estado oligárquico, pero fue incapaz de fundar un estado liberal con democracia limitada e inspirado en los derechos individuales a la vida, libertad y propiedad privada, pero al final de su régimen estatista y dictatorial favoreció a esa misma oligarquía que era enemiga transformándose en una nueva burguesía nacional mercantilista que manteniendo el Statu Quo hasta ahora, pero, hay que reconocer que si no fuera por Velasco en el Perú se hubiese producido una revolución comunista. Del 70 al 80 a raíz de la crisis del régimen velasquista, los partidos políticos civiles retoman el poder con los viejos esquemas estatistas ejecutando algunas tibias reformas resultando ser un régimen seudo democrático del 80 al 90 que produjo que el Perú colapse y que ellos pierdan su rol político de liderazgo y de gobernar el Estado.

Sólo a través de la participación de la población es posible generar una reforma institucional con posibilidades de permanecer en el tiempo. Si lo que se busca realmente es crear las condiciones para el desarrollo económico de un capitalismo sostenido en nuestro país, necesariamente, debemos buscar el contacto permanente con las bases sociales. Solo así estaremos caminando por el otro sendero.

Hernando de Soto ha revolucionado realmente nuestra comprensión de las causas de la riqueza y de la pobreza. Mientras que muchos académicos han señalado y han explicado la importancia de los derechos de propiedad para elevar los estándares de vida, de Soto ha formulado la pregunta crítica de qué es lo que se necesita para que el estado reconozca los derechos de propiedad que funcio- 
nan dentro de las comunidades de los pobres. ¿¿Pueden ellos transformar en capital el control físico "extralegal" de bienes, factor clave para el desarrollo económico sostenido?

De Soto afirmó que pueden lograr estatus legal y desarrollar una guía al "proceso de capitalización" para los países pobres. En su activismo y en su libro El Otro Sendero, Hernando de Soto ha hecho mucho más que aplicar las lecciones de la economía a los viejos problemas; él ha hecho nuevas preguntas y ha proporcionado una nueva comprensión y una nueva esperanza de transformar la pobreza en riqueza.

El Perú de hoy está dividido estructuralmente a raíz del desborde popular señalado en "El Otro Sendero". Realmente hay dos países: el Perú formal, liderado y gobernado por la partidocracia que puede seguir gobernando para desgracia del Perú, y el otro, el Perú informal que ha transformado la realidad del país con su liderazgo político y social.

Su energía productiva y enorme fuerza transformadora y económica han cimentado una república dinámica y vigorosa que subyace, pero que se mantiene excluido y marginado porque no hay un liderazgo político, visión programática y decisión de articular un proyecto político nuevo para fundar una nueva república capitalista liberal de gobierno y democracia limitada (DE SOTO, 2004).

Este Perú informal no está representado por la partidocracia, pero tampoco quiere estar representado por esta casta política sino que quiere salir de su estado de marginación y exclusión para florecer como una nueva república diseñando un nuevo estado con un nuevo régimen de gobierno limitado y una sociedad capitalista de libre mercado auténticamente popular. Según "El Otro Sendero" en la estructuración política, social y económica del Perú informal esta la base social, la fuerza política para fundar una nueva república con la visión y la misión de estructurar al Perú en un estado nacional nuevo, no excluyente y de gobierno limitado (DE SOTO, 2004).

\subsubsection{Las Ventajas de la Formaliza- ción en el Perú}

\section{A. Propiedad Formalizada como Capi- tal Activo}

En el mundo actualmente el capitalismo está viviendo su crisis. Después de la caída del muro de Berlín el capitalismo quedó como la forma más viable de reconstruir y organizar una economía moderna. En occidente los empresarios se preocupan cada vez más porque el hecho de implantar un capitalismo en gran parte del mundo y que éste fracase, tienda o lleve a las grandes economías a una recesión.

Lo que impide a los países tercermundistas beneficiarse del capitalismo es la incapacidad de producir capital. El capital al ser la fuerza que eleva la productividad del trabajo, crea riqueza y por lo tanto es la base del progreso y también es lo que estos países no pueden producir, aunque practiquen las actividades de una economía de este tipo. 
Los países pobres tienen los activos para hacer del capitalismo un éxito, sin embargo en estos países lo que existe y trunca el desarrollo del capital es la posesión defectuosa. No existen en estos países derechos que estén debidamente documentados, esto hace que las posesiones sean activos que difícilmente se convertirán en capital. Lo que sucede en occidente es que todo está representado con un documento de propiedad, lo cual ayuda a que los activos lleven una vida paralela a su existencia material. Lo que pasa en el tercer mundo y en los países que apenas salen del comunismo es que al no tener la representación documentada de su propiedad, se dice que las empresas están subcapitalizadas, es decir en conclusión tenemos que sin una debida representación los activos son capital muerto. (DE SOTO, 2004).

El capital puede ser extraído a partir de los activos, sin embargo sólo en occidente existe el proceso por el cual se transforma lo invisible en visible. Las fallas económicas de los países pobres no se heredan ni por la cultura ni por la genética.

Cuando el occidente empezó a tener éxito con el sistema capitalista fue cuando se universalizó la propiedad formal.

Existen cinco necesidades de la propiedad formal como capital activo:

- Corrección en la Información Ausente.

- El Capital como mecanismo de dinámica comercial.
- Estabilidad y Lucidez Política.

- Las Lecciones no aprendidas en la historia de los Estados Unidos.

- El Fracaso Legal: por qué las leyes de propiedad no funcionan fuera de occidente. (DE SOTO, 2004).

\section{CONCLUSIONES}

El Análisis Económico del Derecho, es una metodología, que se orienta a la creación de modelos tendientes a evaluar rigurosamente los efectos económicos producidos por las leyes. Como en el presente caso de investigación, identificando al territorio comunal, como una externalidad en consecuencia, se puede predecir y prevenir la conducta humana ya que analiza ex ante (antes de que ocurra), a diferencia del derecho ex post (después de ocurrido).

A la luz de los principios del Análisis Económico del Derecho las externalidades del Territorio Comunal Titulado al amparo de las normas establecidas en la Ley 24657 y a la vez nos ha permitido establecer la necesidad de fortalecer la seguridad jurídica a través de la inscripción como valor económico de la propiedad.

Es una demanda imperativa de parte de los comuneros de la región y el Perú, que el Gobierno implemente una Política Pública de reforma normativa del territorio comunal, tendiente a favorecer a este importante segmento poblacional. Significando 
esta reforma, la posibilidad de la Parcelación del Territorio Comunal una vez adoptado el acuerdo en Asamblea General de comuneros calificados, generándose Títulos individuales que finalmente terminen con acogida registral, fortaleciendo de esta manera la Seguridad Jurídica.

\section{BIBLIOGRAFÍA}

1. ALBALADEJO, Manuel (1994) Derecho Civil, Derecho de Bienes. José María Bosh Editor S.A. Barcelona, España.

2. BULLARD GONZALES, Alfredo (2006) Derecho y Economía. El Análisis Económico de las Instituciones Legales. Palestra Editores. Lima, Perú.

3. CACHANOSKY, Juan (1991), Articulo de la Revista Universitaria Investigador y Profesor en ESEADE (Argentina) Facultad de Ciencias Económicas de la Universidad Católica. Rosario, Argentina.

4. CALABRESI, Guido y MELAMED, Douglas (1972) "Property Rules, Liability Rules and Inalienability: One View of the Cathedral". Harvard Law Review. Volumen 85.

5. CASTILLO, Mario y VASQUEZ, Ricardo (2006). Analizando el Análisis. Autopsia del Análisis Económico del Derecho por el Derecho Civil. Editorial de la Pontificia Universidad Católica del Perú. Lima, Perú.
6. COASE, Ronald (1994) La empresa, el mercado y la ley, Alianza economía.

7. COOTER, Robert y ULEN, Thomas (1998). Derecho y Economía, Primera Edición. Fondo de Cultura Económica. México.

8. DE SOTO, Hernando (2004) El Misterio del Capital Editorial Planeta Colombiana S.A. Bogotá, Colombia.

9. FARRANDO, Ismael y MARTINEZ, Patricia (2000) Manual de Derecho Administrativo Ediciones Depalma, Buenos Aires Argentina.

10. GONZÁLES, Ghunter (2002) Tratado de Derecho Registral Inmobiliario. Jurista Editores. Lima, Perú.

11. GUASTINI, Ricardo (2008) La Interpretación de la Constitución. En: ORTEGA, Santiago (compilador). Interpretación y Razonamiento Jurídico. Hermeneia Editores S.A.C. Vol.1 Pp. 60. Lima, Perú.

12. LACRUZ y SANCHO REBULLIDA, (1984) Derecho Civil, Cuadernos Civitas (1984) Madrid España.

13. MALPARTIDA, Víctor (1996) Introducción al Derecho Económico. Análisis Económico del Derecho y Derecho al Desarrollo. Editorial San Marcos EIRL. Lima Perú.

14. MISHAN, E. J. (1971) Journal of Economic Literature, vol. IX, 
N. ${ }^{\circ}$. Adaptación al español de Federico Aguilera Klink (solo de las páginas 18-21).

15. POSNER, Richard (1998) El Análisis Económico del Derecho. México D.F. Fondo de Cultura Económica. pp. 29-31. México D.F.

16. ROEMER, Andrés (1994) Introducción al Análisis Económico del Derecho Primera Edición. Fondo de Cultura Económica. México.
17. SÁNCHEZ, Román (2010) El Registro Público de la Propiedad, Buenas Tareas. Buenos Aires, Argentina

18. STIGLITZ, Joseph (2002) El Malestar de la Globalización. Ed. Aguilar. Altea Taurus, Alfaguara S.A. P.15. Buenos Aires, Argentina.

19. TORRES, Jorge (2001) Ensayo Acerca del Análisis Económico del Derecho Publicado en www.teleley.com/articulos/art-ae.pdf. 
